\title{
NOTES AND STUDIES
}

\section{THE METRICAL ENDINGS OF THE LEONINE SACRAMENTARY. II.}

IN a former number of the JoURnAL ${ }^{1}$ I discussed the various forms assumed by the final phrases of the prayers and prefaces of the Leonine Sacramentary (Leon.), and compared the results of an examination of these phrases with those recorded by M. Louis Havet as to the final phrases of the Letters of Symmachus. In that note I mentioned two questions which seemed to deserve further consideration, and to which I hoped to return. On one of these questions judgement had already been given by an authority which may be regarded as decisive. Professor Wilhelm Meyer has very kindly referred me to a passage in his paper, Das turiner Bruchstuck der altesten irischen Liturgie", containing a concise description of the rhythm of the prayers of Leon., taken as a whole. That description seemed to me, so far as my investigations had enabled me to form an opinion on the matter, to set forth the facts of the case as accurately and as completely as they could be expressed in a single sentence. But it still seemed to be worth while to pursue the task which I had begun, not only because it was necessary to ascertain the facts in detall, with a view to the decision of the second question, but because it seemed that a detailed statement of the facts he had summed up might be of some value, if only by way of illustration of his statement.

I have endeavoured to take account of every phrase ${ }^{3}$ which seems to be followed by a pause, whether such pause would be more or less marked. There are of course a good many cases where the occurrence of a pause is uncertain : and in deciding for or against the inclusion of

'J.T.S vol.v pp. $386-95$.

2 Nachrichten von der Konigl. Gesellsch. der Wissensch. zu Gottingen, I903 (Phalologusch-histonsche Klasse), p. I64.

3 I have omitted phrases where the true reading appeared to be quite uncertain: the number of these is very small. I have omitted also those portions of the Christmas prefaces which are contınuous or almost continuous extracts from Isaiah and from St Luke. These amount to about twenty lines of Muratorn's columns. I have followed, as before, the text of Dr Feltoe's edition. 
such phrases I cannot be sure that my judgement has always been right or consistent. I am inclined to think that mistakes, when I have made them, will generally have been on the side of inclusion. Again, it is probable that my classification of the phrases included in the reckoning is not always free from error or inconsistency. It is most likely that a fresh reckoning would not give exactly the same figures: but I believe that those which are stated in this note are approximately correct, and that the amount of error is not such as to affect the details in any material degree.

The total number of phrases taken into account (including the $134^{\circ}$ final phrases considered in my former note) is $53^{62}$. In the great majority of these cases the phrase ends with a word (or a combination of closely connectcd words) belonging to one or other of the principal types mentioned in the former note. The relative frequency with which the various types of last word occur may be seen from the following table.

Type of last word.
(A) $--\underline{u}$
(B I) $\cup \cup ー \simeq$
(B 2) $-\cup \cup \simeq$
(B 3$)--\cup \longleftarrow$
(C) $-\cup-\longleftarrow$
(D) $\cup--\underline{\cup}$
(E) $---\underline{\cup}$
Unclassed

Total

\begin{tabular}{rcr} 
Final. & Number of phrases. \\
483 & I I 90 & Total. \\
73 & 329 & 1673 \\
228 & 514 & 402 \\
131 & 634 & 742 \\
315 & 778 & 765 \\
46 & 136 & 1093 \\
49 & 232 & 182 \\
15 & 209 & 281 \\
\hline 1340 & 2022 & 224 \\
\hline
\end{tabular}

It will be seen that this table exhibits some differences, in regard to the relative frequency of the various types of last word, between the two classes of phrases. The three types, A, B 2, and $C$, which are predominant in the final phrases, do not occur so frequently in the non-final, or minor, phrases. On the other hand, the proportion of $\mathrm{B}_{3}$ is much greater in the minor phrases than in the final, while $B_{I}$ and $E$ are also more frequent. The cases in which the last word does not exactly conform to any of the principal types, which in the final phrases hardly exceed I per cent., amount in the minor phrases to rather more than 5 per cent. of the whole. Some of these differences might be expected. It is likely that special attention would be given to the regularity and smoothness of the final phrases : and this would naturally result in the avoidance of such forms of last word as those which are denoted in the table by the term ' unclassed'. It is also likely that considerations of quantity would be more carefully observed in the final phrases than 
in the other portions of the text: and to this cause perhaps may be attributed the comparative infrequency in the final phrases of the types $E$ and $B$ I, since the former seems to be merely an accentual equivalent of $\mathrm{C}$, while the same character may certainly be assigned in a considerable number of instances to the type $B$ I.

For the same reason we might expect to find, when we consider the cadences of which the last words are constituent parts, that the cadences of the minor phrases are less strictly metrical in their character than those which mark the endings of the collects and prefaces; that whereas, for instance, it is only very rarely that we find, in the final phrases, a spondee placed before a last word of the type $A$, such usage would be less rare in the minor phrases. And this is certainly the case. But it is also the case that even in the minor phrases the cadences which end with a word of any of the types A, B I, B 2, B 3 are in the great majority of cases metrically regular. Of the 778 phrases which end with a word of the type $\mathrm{C}$, by far the greater part shew before that word a combination of syllables with short penultimate, avolding the faulty cadence of 'trochaeus triplex'. The exceptions to this rule are but little more than 4 per cent. In the majority of the phrases which end with a word of the types $\mathrm{D}$ or $\mathrm{E}$ (accentual equivalents of $\mathrm{C}$ ) the same rule holds good: the proportion of exceptions, resulting in an accentual 'trochaeus triplex' $(\underline{\prime} \underline{ } \mid \underline{\dot{\prime}}-\underline{-} \underline{u})$, is, I think, not more considerable than in the case of $\mathrm{C}$.

The detals with regard to the minor phrases which end with a 'molossus' (A), or with one of its metrical equivalents ( $\mathrm{B} \mathrm{r}, \mathrm{B} \mathrm{2}, \mathrm{B} 3$ ), will appear with sufficient accuracy for the present purpose in the following table. The corresponding details for the final phrases are given in my former note ${ }^{1}$.

\begin{tabular}{|c|c|c|c|c|c|c|c|}
\hline \multirow{2}{*}{\multicolumn{3}{|c|}{ Preceded by - -}} & \multirow{2}{*}{$\begin{array}{r}\text { A } \\
1157\end{array}$} & \multirow{2}{*}{$\begin{array}{l}\text { B I } \\
204\end{array}$} & \multirow{2}{*}{$\begin{array}{r}\text { B } 2 \\
459\end{array}$} & \multirow{2}{*}{$\begin{array}{l}\mathrm{B}_{3} \\
547\end{array}$} & \multirow{2}{*}{$\begin{array}{l}\text { Total } \\
23^{6} 7\end{array}$} \\
\hline & & & & & & & \\
\hline$"$ & $"$ & レレu & 5 & I9 & 0 & I & 25 \\
\hline " & ", & -uv & I & 67 & I & I & 70 \\
\hline , & " & レレー & 0 & Io & 1 & 2 & I 3 \\
\hline ," & " & $-\smile ー$ & 0 & 24 & 0 & 7 & $3 t$ \\
\hline$"$ & ", & -- & 20 & 5 & 51 & 69 & 145 \\
\hline " & " & $\cup \smile$ & 7 & 0 & I & 3 & I I \\
\hline ", & " & $u-$ & 0 & $\circ$ & I & 4 & 5 \\
\hline & & & 1190 & 329 & 514 & 634 & 2667 \\
\hline
\end{tabular}

It will be seen that by far the greater part (rather more than 88 per cent.) of the whole number of these phrases exhibit cadences which conform to the standard of the metrical rules and examples of Martianus Capella, 
cited in my former note ${ }^{1}$. Of the remainder the greater part, while faulty according to this metrical standard, yield cadences which are the accentual equivalents of the regular metrical forms. In 145 instances the place which should be filled by a trochee is occupied by a spondee accented on the first syllable; in sixteen others ${ }^{2}$ by a word of the form $\dot{\sim} \cup$ or $\dot{v}-$. The substitution of a tribrach for the trochee is regarded by Martianus Capella as regular in the case of $\mathrm{B} \mathrm{I}$, and the same substitution is apparently not infrequent in the letters of Symmachus before a last word of the types $A$ and $B$ 3. The three cases in which a dactyl takes the place of the trochee before $\mathrm{A}, \mathrm{B} 2$, and $\mathrm{B} 3$ are 'sanaque convertant', 'praecipit officio', and 'frequentia sollemnia'. In the first of these some stress would fall on the syllable preceding the enclitic: in each of the others a very slight change of reading gives a radence metrically regular?. The ten cases in which an anapaest or cretic is combined with $\mathrm{B} 2$ and $\mathrm{B} 3$ do not (save perhaps in one unstance) appear to give a regular cadence appropriate to the resolved molossus, whether the test be that of quantity or of accent. But six out of the ten should probably be placed in another class. In them the group of syllables which has the metrical value of $\mathrm{B}_{3}$ is made up of two disyllables, and has the accentual value of a double trochee. They are, that is to say, really cases of accentual cadence of another type 4 .

So, no doubt, are all the ror cases in which $\mathrm{B} I$ is combined with a preceding dactyl, anapaest, or cretic: for $\mathrm{B}_{\mathrm{I}}$, as has been already stated in my former note, must frequently be regarded as the accentual equivalent of $\mathrm{C}$. And it may, I think, be likely that the apparent regularity of some of the phrases under $B_{I}$ is unreal, and conceals what from the metrical point of view may be described as a double fault, the last word of the type $\dot{u} \cup \mathcal{u}$ being regarded as a double trochee, and combined with preceding $\lrcorner \cup$ or $\mathcal{-}-$, so producing an accentual ' trochaeus triplex'. If no allowance be made for such cases, the proportion of metrical regularity under $\mathrm{B}_{\mathrm{I}}$ would appear to be as great in the minor as in the final phrases. But even if a deduction

1 J.T.S. vol $\vee$ p. 390 . I have here reckoned as metrically regular a small number of cases in which the cadence includes a hiatus : this seems to be justified by the example 'regere animorum'.

'In five of these cases the word in question is 'prece' or 'preces'. The spelling usual in the MS suggests that the first syllable of either word might be regarded as long.

'The substitution of 'frequentata' for 'frequentia' and of 'praecepit' for 'praecipit' would in each case improve the sense of the text. The latter change was actually made by the earlier editors.

- One or two of the cases in which B 3 is combined with a preceding trochee, metrical or accentual, should perhaps be ranked with these, in respect to the form of their last words. 
on this score be made on a liberal scale from the $20_{4}$ cases of metrical regularity, the majority of phrases under $B_{I}$ will still be metrically regular ${ }^{1}$.

The type $\mathrm{B} 2$, whenever (as is practically always the case) the second of its four syllables is the one accented, is the accentual equivalent of $\mathrm{B} 3$. From this point of view it might be said that all or nearly all the phrases under $\mathrm{B} 2$ are really accentual. But the distinct recognition given to the type $\mathrm{B} 2$ in the metrical system formulated by Martianus Capella, and the frequency with which the type appears in the final phrases of Leon., seem to tell in favour of the metrical character of the group as a whole. Certainly, whether by accident or design, the great majority of the phrases which it includes have a cadence which is metrically regular: the same remark applies to the group under $B$, and still more strongly to that under A. Taking the whole of the four groups together it seems impossible to suppose that without design and careful attention the metrical fault of placing a spondee before a last word of any of the four types could have been avoided so consistently.

The 'unclassed' forms might be simply set aside as irregular or exceptional: but it is worth while to see whether their cadences correspond with those of the principal groups. About 20 per cent. yield a cadence which (save for the position of the caesura) is metrically regular ${ }^{2}$, about $5^{\mathrm{I}}$ per cent. a cadence which is accentually regular?. Almost all the rest end with a word or group of five syllables, of which the penultimate is short and the ante-penultımate either long or accented 4 There are also a few cases where the reading is uncertain.

It appears then, as the result of this examination, that the same system which prevails in the final phrases of Leon. prevails also throughout the text of the book as a whole: that while the minor phrases (as we might expect) shew a larger proportion of exceptions to the metrical rules than the more important cadences, the phrases which are regular both by accent and by quantity far outnumber those which have only accentual regularity or which shew any other departure from the ordınary types. I now turn to the other question, whether particular sections of the

1 The rarity of the 'trochaeus triplex' (metrical or accentual) formed with last words of the types C, D, E suggests that it is unlikely that the cases of its appearance among phrases ending with $B$ I would exceed ro per cent. of the whole number ( 120 ) of the phrases in which $B I$ is combined with a preceding foot appropriate to a double trochee.

e.g. 'muneris gustu', 'effici tribuas', 'suffragantibus meritis', 'fructuum qualitas', 'passionis trumphum'.

' e.g. 'laetamur gustu', 'praeside greg1', 'cura regentium', 'adsıt humılıbus', 'terram promissionis'.

' e g. 'commissi moderaminis', 'adhuc clausus utero', 'persecutıone lapidatus est', ' 'ngrati beneficis', 'patientiam tolerant1ae'.

VOL. VI.

$\mathrm{C}$ C 


\section{$3^{86}$ THE JOURNAL OF THEOLOGICAL STUDIES}

book shew any considerable variation in respect to the observance of the system.

The results of the survey already made suggest that the principal points to which attention should be given are these :

I. The frequent combination with A, B I, B 2, or B 3 of an accentual

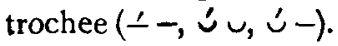

2. The frequent occurrence of last words of the type $\mathbf{E}$.

3. The frequent occurrence of the 'trochaeus triplex', whether metrical or accentual.

4. The frequent occurrence of last words or groups of syllables of 'unclassed' form.

It may also be worth while to take note of any unusual frequency of particular types of last word, and of cases of hiatus.

For the purpose of this enquiry the distribution of the contents of the book into large sections assigned to the various months from April to December is not of much account : but it may be well to state briefly some general results with regard to these divisions. If we take as regular all the phrases (save those in which the cadence supplies one of the few instances of hiatus) which end in a combination of A, B I,

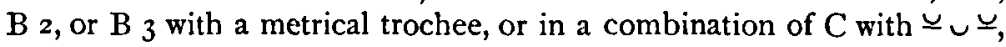
and as irregular or doubtful all other phrases, the proportion of the regular and urregular phrases may be stated as follows for the several months : the figures are approximate only.

$\begin{array}{lcc} & \text { Regular. } & \text { Irregular. } \\ \text { April } & 73.5 & 26.5 \\ \text { May } & 77.4 & \mathbf{2 2 . 6} \\ \text { June } & \mathbf{7 7 . 1} & \mathbf{2 2 . 9} \\ \text { July } & 80.7 & 19.3 \\ \text { August } & 83.5 & 16.5 \\ \text { September } & 81 & 19 \\ \text { October } & 76 & 24 \\ \text { November } & \mathbf{7 9 . 3} & 20.7 \\ \text { December } & 77.5 & \mathbf{2 2 . 5}\end{array}$

The high percentage of irregularity in the April section ${ }^{1}$ is the more remarkable when we take into account the fact that the section includes few liturgical forms of any considerable length, so that the proportion of final to minor phrases is larger than in most of the months.

All the masses in this section are for festivals of saints : in a few forms the names of saints occur, but there are no headings assigning

1 The beginning of this section, and therefore its heading, are lost : but it may fairly be assumed that it was assigned to this month. 
the masses to particular days. One mass appears to have been intended for use on a feast of St Peter in a church containing relics of the Apostle ${ }^{1}$. The irregularities are distributed pretty evenly among the various masses, few of which are without two or three instances of departure from rule. The number of phrases ending in 'unclassed' forms is unusually large, and six out of the twenty-seven cases in which $A$ is combined with an accentual trochee occur in this group of masses ${ }^{2}$, which also includes several of the cases of hiatus. The combination of B I with a preceding dactyl is frequent. The masses which shew most irregularity in proportion to their length are those numbered xvii, xix, and xxxix.

The masses assigned to May are all for Ascensiontide and Pentecost. They are on the whole fairly regular, but few are without an instance of the combination of $\mathrm{B} 3$ with a preceding spondee. The 'trochaeus triplex' is almost entirely absent, and there are but few 'unclassed' forms. The masses for Pentecost are rather more regular than those which precede them: but the difference is not marked.

The June section and all the other remaining sections (except October) are wholly or partially occupied by collections of masses for festivals. It may be most convenient to consider these together, leaving the other portions of the text for later consideration. The June masses are connected with the Nativity of St John Baptist, the feast of St John and St Paul, and that of St Peter and St Paul. 'The first group is, save for the occurrence of $\mathrm{D}$ and $\mathrm{E}$, very regular: there are few cases of the accentual trochee, none ( $I$ think) of the 'trochaeus triplex', and but few ' unclassed' forms. D and $\mathrm{E}$ are, however, rather frequent. These types appear less frequently in the masses of St John and St Paul : but here the accentual trochee is more plentiful, mostly in combination with $\mathrm{B} 3$ and $A$. 'The 'trochaeus triplex' is again absent. In the masses of St Peter and St Paul there are some cases of repetition : e. $g$. the preface which appears in that numbered i. appears again (with an addition marked by regularity of cadences) in that numbered xiv. The preface of no. $v$. contains a large proportion of accentual cadences: but some of these mark pauses of the slightest kind. In some of the masses (iii, xiv ${ }^{3}, \mathrm{xv}, \mathrm{xix}, \mathrm{xx}, \mathrm{xxii}, \mathrm{xxviii)} I$ have noted no instances of accentual trochee. The 'trochaeus triplex' is not altogether absent,

'A marginal note indicates its use 'in dedicatione'. This mass (no xxxiv) is fairly regular in its cadences. These, however, include one case of "trochaeus triplex' and one 'unclassed' ending.

Two of these are in final phrases.

- Save in the portion of the preface common to $i$. In that portion a cadence with accentual trochee is substituted for one of 'unclassed' form by a very slight change.

$$
\text { C c } 2
$$


but there are few cases in the whole group. $\mathrm{E}$ is rather more frequent in the last half of the series than in the first, but never very prominent.

For July there is a group of masses for the feast of the martyrs commemorated on July ro. These shew a few instances of 'unclassed' forms, a few of accentual trochee, and a moderate proportion of $\mathbf{E}$. I have not noted more than two instances of the 'trochaeus triplex'. The August section includes several series of saints'-day masses, and no other matter. In all the series which it contains the proportion of irregular or accentual cadences is very small; and the same remark applies to the festival masses of September. The series for the 'Natale Basilicae S. Angeli in Salaria', except for a few phrases ending in D or $\mathrm{E}$ (most of which are in a single mass), seems to be entirely free from non-metrical cadences.

The November section is also entirely made up of masses connected with festivals of saints. It begins with two for the feast of the "Quattuor Coronati', which save for a doubtful case of the combination of $A$ with a preceding spondee, two phrases ending in $\mathrm{D}$ and one in $\mathrm{E}$, and an 'unclassed' form which gives a good accentual cadence, are regular throughout. The five masses of St Cecilia, in which a large proportion of the phrases end with a word of the type A, are on the whole extremely regular in their cadences; those of the fourth and fifth are almost without exception metrical: the other three masses contain a few instances of 'unclassed' forms, three or four of a spondee before $\mathrm{B} 2$ and $\mathrm{B}_{3}$, and three cases of 'trochaeus triplex'. The first has also two cases of hiatus. $\mathrm{D}$ and $\mathrm{E}$ each occurs once in the five masses. $\mathrm{B} I$ is rare, and is only once combined with a foot other than - $u$ or $\cup \cup u$. The prefaces, which are of considerable length, are practically as regular in the form of their cadences as the collects. The same regularity is found in a rather less marked degree in the group of masses of St Clement and St Felicitas. D and E appear rather more frequently, and there are fewer appearances of $\mathrm{A}$. In the mass of St Chrysogonus and St Gregory, D stands at the end of two phrases, B I is combined with a dactyl, and there is one case of hiatus: the remaining fifteen phrases are metrical. The four masses of St Andrew also contain a large proportion of phrases ending in $A$ : they have rather a larger proportion of $\mathrm{D}$ and $\mathrm{E}$ than the preceding groups, but no 'unclassed ' forms, only a single case of an accentual trochee, and none of the 'trochaeus triplex'.

The Christmas masses shew a larger proportion of departures from the metrical standard: but in four of the nine which form this group (nos. iv, $v$, vin, $1 x$ ) the non-metrical phrases are very few. In the first of the series the proportion of $\mathrm{D}$ and $\mathrm{E}$ is rather large, and the group contains perhaps rather more than a fair share of the examples of hiatus. 
It has also several 'unclassed' forms, and four or five cases of the accentual trochee. The masses for the feasts of St John and of the Holy Innocents are for the most part regular, save for the occurrence of $\mathrm{D}$ and $\mathrm{E}$, the latter of which is rather frequent. The last of the four masses has two cases of a spondee in combination with A. Takıng the festival masses as a whole, the level of metrical regularity seems to be farly maintained throughout. The highest point seems to be reached in the August and November groups, the lowest in the group of masses for the feast of St Peter and St Paul (or rather in the least regular masses of that series) and in the least regular of the Christmas masses.

The October masses are of a different class. They consist of two groups, one 'de siccitate temporum', the other (in which the last mass has special reference to St Silvester) 'super defunctos'. The masses 'de siccitate temporum' contain an unusually high proportion of $\mathrm{D}$ and $\mathrm{E}$, and include the only cases $\mathrm{I}$ have noted in which $\mathrm{B} 3$ is combined with an anapaest or tribrach, and one of the few instances in which it is preceded by a cretic. There are also some 'unclassed' forms of ending. The masses 'super defunctos' also have a rather high proportion of $\mathrm{D}$ and $\mathrm{E}$ : but otherwise their cadences are with few exceptions metrically regular.

The masses ' $1 \mathrm{n}$ ielunio' which appear in the September and December sections contain a considerable proportion of 'unclassed' forms, of which only a small number give a metrical cadence. The accentual trochee, though not very frequent, is more prominent than in most of the festival masses, and the 'trochaeus triplex' is found several times in the September group. Some of the masses in both groups have a large proportion of $\mathrm{D}$ and $\mathrm{E}$. The average of metrical regularity for the whole of the two series is however farrly high.

The 'Consecratio Episcopi' and 'Benedictio Diaconi' which appear in the September section are metrically regular almost throughout. Each has a large proportion of $\mathrm{A}$, and a very small proportion of $\mathrm{I}$ ) and $\mathrm{E}$. The 'Consecratio Episcopı' includes three 'unclassed' forms, which occur together near the end of the long consecratory prayer. These all give a metrical cadence, but one of them (which is an instance of hratus) yields a 'trochaeus triplex'. In the 'Consecratio Presbyterı ' the proportion of $\mathrm{A}$ is much smaller, that of $\mathrm{E}$ larger, than in the forms for Bishop and Deacon. 'The 'Benedictio Virginum' contains several 'unclassed' forms, of which not quite one-half give an ordinary metrical cadence. Nether in it nor in the 'Benedictio Nuptialis' is there the same absence of accentual trochee which marks the Ordination forms : but the cases of this fault are rare in both. In the five groups of prayers taken as a whole the standard of metrical regularity is high 
Judged by the same rule which I have applied to the monthly sections the 'regular' phrases are about 8r per cent. of the whole number.

The masses 'in Natale episcoporum' which are placed in the September section are as a whole equally regular, when judged by the same test. The proportion of 'unclassed' forms is low, that of D and $\mathrm{E}$ not high. In the mass numbered vi. there is a large proportion of $\mathrm{E}$, and that numbered $v$. contains one prayer which is notably irregular in its cadences. The most regular masses of the series are perhaps those numbered $x, x i$, xii, and xxii. $B I$ is joined with a trochee in about two-thirds of the cases in which it occurs : and there are sufficient instances of the 'trochaeus triplex' formed with $\mathrm{C}$ to suggest that some of these apparently regular phrases are really accentual. But even allowing for this possibility the metrical regularity of the group is high.

Almost the same general remarks will apply to the 'Orationes et preces diurnae' which form the greater part of the section assigned to July. The proportion of $D$ and $E$ is rather less than in the masses ' in Natale episcoporum', that of 'unclassed ' forms rather greater: the same doubt attaches to the apparent regularity of the phrases ending with $B$ I. The masses which shew the least proportion of irregularity from the metrical point of view are those numbered xxviii-xxxı and xxxvixxxviii. There are two prefaces in this section which have been frequently noticed as abnormal in tone; they are those of the masses numbered iii. and $x x$. The former contains two or three irregular phrases, but is for the most part metrical throughout ${ }^{1}$ : the latter, whle also metrical in the main, has a good many accentual phrases. These, however, are almost all taken from Scripture, the number of citations being large, while the words cited do not always lend themselves to the formation of metrical cadences. The writer, while he has apparently sometimes modified the words he cites, seems to have contented himself with securing a rhythmical cadence, even though the form of it were a little rugged, and to have refrained from alteration beyond what this required. The irregularities which the preface contains are rather numerous : it includes, for instance, five ${ }^{2}$ of the cases in which $A$ is combined with $\mathcal{-}$-or $\cup \cup$ : but I am inclined to think that this is due to the number of citations, rather than to disregard of the ordinary forms.

In this survey I have, I think, taken note of all the principal points in which the various portions of the book can be said to differ in regard to their observance of the rule, and of the extent of the variation. The general result of the scrutiny is in one sense negative. It does not

\footnotetext{
' So is that of the first mass of the series, which though less controversial in character presents some points of resemblance to the two in question.

Four of these are in citations.
} 
appear that the variation is in any group of masses so marked in character or in degree as to warrant the opinion that the group stands outside the range of the system: the same system which prevails in the book as a whole prevails also in every group, and throughout every group. Further, though the observance of the system may fairly be said to be more exact in some parts of the book than in others, the variation in this matter is never very great. The April masses, perhaps, supply an exception : not only in respect of their cadences, but in general arrangement, they form the least orderly element in the book. But apart from this division, or even including it, the general impression which is left by a comparison of the various sections is not that of a collection of material of various sources and dates brought together without revision. It is an impression of uniformity rather than of difference-of such uniformity as might be found on the one hand in a collection of material composed by different writers guided, as to the forms of their phrases, by a common usage, or on the other in a collection of forms which may have been gathered from different sources or based on material of different dates, but which have for the most part been subjected to revision by a single hand. At the same time there seems to be discernible, behind this general uniformity, a certain amount of variation between particular groups of masses, or between particular prayers which are parts of the same group, such as may support an opinion, formed on other grounds, as to the date at which particular forms or groups of forms were originally composed, or the date and character of the material from which they have been constructed.

H. A. WILSON.

\section{THE EPISTLE OF ST JUDE: A STUDY IN THE MARCOSIAN HERESY.}

\section{The date of the Epistle.}

There are two passages in the Epistle which point to its postapostolic origin. The writer is moved to action by the danger which threatens 'the faith once for all delivered to the saints' (v. 3). It is clear that the faith was already recognized as a fixed tradition, treasured by the Church as the safeguard of the 'common salvation'. The writer also bids them remember 'the words which had been spoken before by the apostles' (v. I 7 ), an expression which implies that the apostolic writings already enjoyed some kind of canonical authority in the Church. It is almost the same view of apostolic times which is taken by the 